\title{
ADJUSTMENT FOR SHAPE RESTORATION AND FORCE CONTROL OF CABLE ARCH STAYED BRIDGES
}

\author{
A.A. MANGURI ${ }^{1}$, A.S.K. KWAN ${ }^{2} \&$ N.M. SAEED ${ }^{1}$ \\ ${ }^{1}$ Civil Engineering Department, University of Raparin, Kurdistan, Iraq. \\ ${ }^{2}$ Cardiff School of Engineering, Cardiff University, U.K.
}

\begin{abstract}
Cable arch stayed bridges are one type of tensile structures, and there are increasingly such structures constructed. Their performance relies on how they are designed. This type of structures can suffer big deflections under load, in this situation the displacements may need to be reduced. Sometimes, it may be necessary to control internal force of a specific cable so the cable force remains within the desired limit. More study need to be done to develop the techniques that are available for such adjustments. This paper deals with theoretical and experimental adjusting of two physical models, and the linear and nonlinear geometrical behavior of cable (arch) stayed bridges. It was concluded that the techniques of adjustment were practical and efficient to reduce, eliminate shape distortion, and control internal bar force of both structures. For structures that behave linearly, it is easier to get the target (displacement or force), but for non-linear structures one iteration of adjustments was not enough to get the displacement target. Through the techniques of the internal bar force adjustment, the amount of force can be reduced even to the zero, e.g. in case of replacing damaged members.

Keywords: force method, internal force adjustment, shape restoration, tensile structures and cable arch stayed bridges.
\end{abstract}

\section{INTRODUCTION}

Nowadays, the tendency to build megastructures is increasing; some of them need to have large spans, for instance cable-stayed bridges. Nonetheless, there are applications of structural engineering where tolerances of structural shape and internal forces, under changing service conditions, are significant, since it has effects on the structure's serviceability limit state Saeed [1]. When structures composed of beam members, such as arch cable stayed bridges are used for a long time under different loadings or due to the harsh environment, some of the nodes (deck or arch) could undergo a big deflection, or some of the members experience large force, leading to change in some specific bars/cables in cable structures. Cables may also face slack, which means they effectively become structurally non-existent, so they would have to be shortened. For solving the problem of high deflection and achieving desired amount of force, the techniques of adjustment can be applied.

Ziegler [2] and Shea et al. [3] defined the technique of adjustment as the process of small changes or movements that improve the current performance or achieve a desired outcome or reduction, or even elimination of the structural deformation caused by external disturbances. The technique of adjustment can be done by altering member length, which is done by actuators [4-8]. There are three types of adjustments, namely, external nodal displacements, internal bar force adjustments and a combination of both. The desired type depends on the function of the structure being adjusted.

The idea of controlling was introduced by Weeks [9], while Ziegler [2] and Irschik [10] reviewed the recent studies in detail, and an analytical procedure was introduced by Haftka and Adelman [4]. Many attempts were made to control all types of adjustment as joint dis- 
placement, bar force and to simultaneously control joint displacement and bar force. Firstly, in terms of external nodal displacement controlling, researchers tried different ways and some developed the others techniques. Saeed and Kwan [11] say external nodal displacements can be controlled via altering the length of some active bars. Passive control strategy was discussed by Irschik [10]. Saeed and Kwan [12] derived an equation to calculate elongation required to attain the desired nodal positions, which has been used in this paper. Secondly, there are a few studies conducted concerning bar force control regardless of the nodal displacements, as Kwan and Pellegrino [7] controlled bar force in a prestresable structure and Saeed and Kwan [11] also conducted the same type of adjustment, and those techniques have been used in this paper as well. Lastly, in terms of simultaneous joint displacement and bar force control, You [13] worked on a prestressed cable structure; where he controlled the displacements of a specific node, and the internal forces in all members were satisfactorily above the desired level, external force was not taken into account. Saeed and Kwan [11] developed the technique, which further took into account external load.

The purpose of this paper is theoretical and experimental nodal displacement and internal bar force control of an arch cable-stayed bridge. For this purpose two structures were manufactured in the laboratory of the School of Engineering at Cardiff University. Structure 1, as shown in Figure 1, is expected to behave linearly due to a stiff overhead beam acting as support, whereas Structure 2 is projected to behave as a geometrically non-linear structure, as shown in Figure 2.

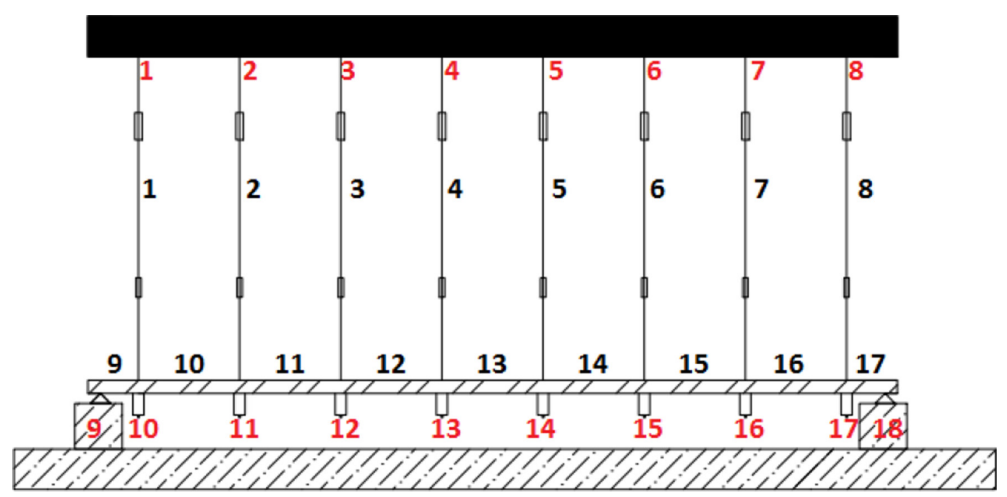

Figure 1: Cable stayed bridge (Structure 1).

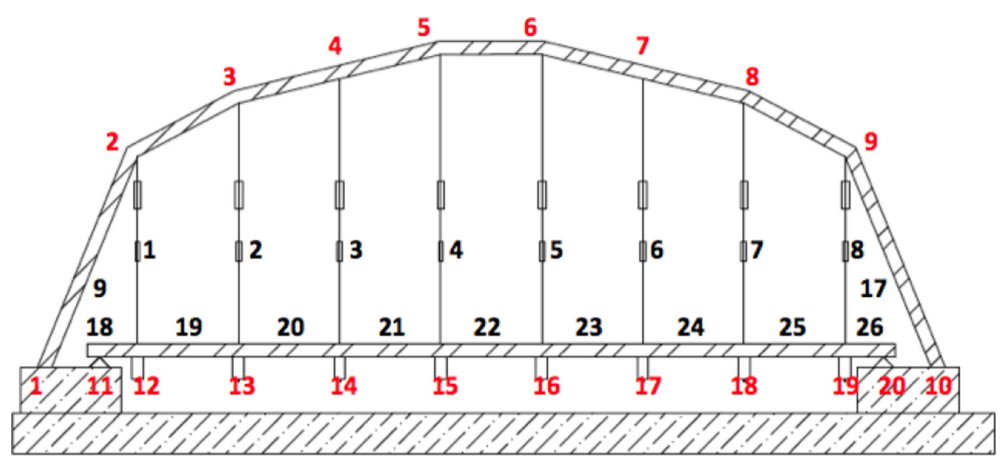

Figure 2: Cable arch stayed bridge (Structure 2). 
The outline of this paper is as follows. The techniques of calculation required amount of actuation for the purpose all three types of controlling is introduced in Section 2. Section 3 shows the detail of physical model of the tested structures. Section 4 presents the theoretical and experimental results of adjustment and discussion for both structures, while a concluding summary is presented in Section 5.

\section{CALCULATION OF ACTUATION FOR THE CONTROLLING PURPOSE}

\subsection{External nodal displacement adjustment}

This type of adjustment, which can be done by eqn (1) Saeed and Kwan [12] is vital for shape critical structures when their shape is made imperfect by unexpected loads or a harsh environment. This could be structures such as antenna, or flexible structures where the 'out of shape' can consequently cause stresses to be too high in some components. The governing equation is

$$
\mathbf{e}_{0}=\mathbf{Y}^{+}\left\{\mathbf{d}-\mathbf{d}_{\mathrm{P}}\right\}
$$

where $\mathbf{e}_{\mathbf{o}}$ is the (total) amount of actuation, required to produce the desired displacement, or at least the best result, $\mathbf{Y}=\mathbf{B}^{+}-\mathbf{B}^{+} \mathbf{F S}\left(\mathbf{S}^{\mathrm{T}} \mathbf{F S}\right)^{-1} \mathbf{S}^{\mathrm{T}}$ (as derived by Saeed [1]), $\mathbf{B}^{+}$is the pseudo-inverse of compatibility matrix $\mathbf{B}, \mathbf{F}$ is the flexibility matrix, $\mathbf{S}$ is the states of self-stress and equal to nullspace(A), and $\mathbf{A}$ is the compatibility matrix. The size of $\mathbf{Y}$ depends on number of joints that needed to be adjusted, which represents number of rows and number of bars that are involved to alter their length; they represent number of columns of $\mathbf{Y}$ matrix. $\mathbf{Y}^{+}$is the pseudo inverse of $\mathbf{Y}$ ( $\mathbf{Y}$ may not be square or even not a full rank), thus it gives the least square solution to $\mathbf{e}_{\mathbf{o}}$, and $\mathbf{d}_{\mathrm{P}}=\left[\mathrm{B}^{+} \mathbf{F}-\mathbf{B}^{+} \mathbf{F S}\left(\mathbf{S}^{\mathrm{T}} \mathbf{F S}\right)^{-1} \mathbf{S}^{\mathrm{T}} \mathbf{F}\right] \mathbf{t}_{\mathrm{A}}$ (as derived by Saeed [1]) is the vector of nodal displacements of the structure due only to load, $\mathbf{t}_{\mathbf{A}}=\mathbf{A}+\mathrm{p}, \mathbf{A}^{+}$ is the pseudo-inverse of equilibrium matrix $\mathbf{A}, \mathbf{p}$ is the vector of external loads, and $\mathbf{d}$ is the resultant nodal displacements after some member actuation $\mathbf{e}_{\mathbf{o}}$ (i.e $\mathbf{d}$ is the prescribed displacement) has been applied. The application of this technique is presented in Sections 4.1.1 and 4.1.2.

\subsection{Internal bar force adjustment}

Shape or nodal position for some structures is not crucial, whereas the amount of internal bar forces under external loading is fundamental for example the roof of a stadium when it is carrying loads. In addition, a cable of a bridge when it becomes slack. This theory is applied to control force inside components of structures via using eqn (2) Saeed and Kwan [11]. Changing the length of at least one bar has effect on the force inside itself and the other bars.

$$
\mathbf{e}_{0}=\mathbf{Z}^{+}\left\{\mathbf{t}_{\mathrm{P}}-\mathbf{t}\right\}
$$

where $\mathbf{e}_{\mathbf{o}}$ is the amount of actuation, which is required to give the desired force in the desire members, or at least the best result, $\mathbf{Z}=\mathbf{S}\left(\mathbf{S}^{\mathrm{T}} \mathbf{F S}\right)^{-1} \mathbf{S}^{\mathrm{T}} \mathbf{F} \mathbf{t}_{\mathrm{A}}$ (as derived by Saeed [1]), $\mathbf{Z}$ is a matrix - the columns of which represent the selected members for altering and its rows are the members which their force needed to be adjusted, and $\mathbf{t}_{\mathrm{P}}=\mathbf{t}_{\mathrm{A}}-\mathbf{S}\left(\mathbf{S}^{\mathrm{T}} \mathbf{F S}\right)^{-1} \mathbf{S}^{\mathrm{T}} \mathbf{F} \mathbf{t}_{\mathrm{A}}$ (as derived by Saeed [1], $\mathbf{t}_{\mathrm{p}}$ is the vector of internal force due to the applied load, and $\mathbf{t}$ is the resultant internal forces after some elongation actuation $\mathbf{e}_{\mathbf{o}}$ has been applied (i.e is the prescribed internal bar force). The application of this technique is presented in Sections 4.2.1 and 4.2.2. 


\section{PHYSICAL MODEL OF THE TESTED STRUCTURES}

This section will discuss the structures' geometry, components, material properties and test procedures. Two structures were manufactured and tested in the laboratory of the School of Engineering at Cardiff University. Structure 1 is a linear structure, while Structure 2 is expected to behave a geometrically non-linear fashion, both structures are shown in Figures 1 and 2. The main difference is in overhead support.

Deck beam: The beam is the same for both structures are made of Aluminum and it has a square cross-section $6.5 \times 6.5 \mathrm{~mm}$. The deck beam consists of nine members and ten joints, with the first and the last joints supported on rollers. The distance between the joints is $250 \mathrm{~mm}$ except at the two ends, where the distance is $125 \mathrm{~mm}$.

Cables: The main function of the cables is to transfer loads from the deck to the frames. They are made out of stainless steel and both structures have eight cables. The lengths of the cables in Structure 1 are the same. However, for Structure 2 there are four different lengths with each two positional symmetric cables being the same length. The diameter of the cables is $0.25 \mathrm{~mm}$. The cables have $\mathrm{EA}=9.08 \mathrm{kN}$, while for the beam $\mathrm{EA}=2.96 \mathrm{MN}$ and $\mathrm{EI}=10.4 \mathrm{Nm}^{2}$.

\section{RESULTS AND DECISION}

In this section two experiments were carried out for each Structures 1 and 2, for controlling nodal displacement without regard to the bar force and controlling bar force without regarding to the nodal displacement.

\subsection{External nodal displacement without regard to internal force}

\subsubsection{Structure 1}

In this experiment for Structure 1 joints 10 to 17 on the deck beam were loaded with $40.3 \mathrm{~N}$ downward each. Table 1 shows the results of joint displacement adjustment for Structure 1 after loading. It can be seen that the first and last joints displaced less than $3 \mathrm{~mm}$; the joints that displaced more than that amount were adjusted. Their target displacement was assumed

Table 1: Displacement adjustment for Structure 1 without regard to the bar force.

\begin{tabular}{lllllll}
\hline 1 & 2 & 3 & 4 & 5 & 6 & 7 \\
\hline Joints & $\mathbf{d}_{\mathbf{p}}(\mathrm{mm})$ & Req. d. $(\mathrm{mm})$ & Theo. d. $(\mathrm{mm})$ & Exp. d. $(\mathrm{mm})$ & Cables & $\mathbf{e}_{\mathbf{o}}(\mathrm{mm})$ \\
\hline $10 \mathrm{y}$ & -2.83 & none & -2.1 & -2.57 & 1 & 0 \\
$11 \mathrm{y}$ & -4.03 & -3 & -2.63 & -2.91 & 2 & -1.27 \\
$12 \mathrm{y}$ & -4.14 & -3 & -2.31 & -3.05 & 3 & -1.00 \\
$13 \mathrm{y}$ & -4.28 & -3 & -2.09 & -3.1 & 4 & -1.33 \\
$14 \mathrm{y}$ & -4.25 & -3 & -2.09 & -3.03 & 5 & -1.28 \\
$15 \mathrm{y}$ & -4.13 & -3 & -2.28 & -3.07 & 6 & -1.00 \\
$16 \mathrm{y}$ & -4.05 & -3 & -2.55 & -2.99 & 7 & -1.29 \\
$17 \mathrm{y}$ & -2.96 & none & -2.06 & -2.57 & 8 & 0 \\
& & & Total actuation $(\mathrm{mm})$ & & 7.17 \\
\hline
\end{tabular}


to be $3 \mathrm{~mm}$ (Column 3) and it can be clearly noticed that the target displacement (Column 3) and experimental displacement (Column 5) after adjustment are coincident with the rms error only $0.066 \mathrm{~mm}$. Nonetheless, the difference of theoretical and experimental displacement results after controlling (Columns 4 and 5) are approximately good. It can be said that the linear theory for adjustment works well, in spite of having the small variance between theoretical and practical results, which are common in the analysis theory due to flexibility of the structure and constructing of geometrical model.

\subsubsection{Structure 2}

Table 2 shows the results of two attempts to adjust the displacement of the Structure 2 due to the loading of joints 12 to 19 on the deck beam with $15.3 \mathrm{~N}$ downward each. The reason behind loading with small weight was that the internal forces of the first and the last cables were large. For adjustment might be required to shorten these two cables, which would put them under larger tension.

Table 2 shows that for a geometrically non-linear structure one iteration could be inadequate to get the desired displacement, because a linear adjustment method is being used. As it is clear that the first set of $\mathbf{e}_{\mathbf{o}}$ in iteration 1 gave the discrepancy of results (Column 6) with rms error $2.86 \mathrm{~mm}$ with desired displacement (Column 3), but, in iteration 2, the size of rms error falls greatly from $2.86 \mathrm{~mm}$ to $0.22 \mathrm{~mm}$ (Columns 3 and 9). So the important message is, a linear adjustment method can still be applied for a geometrically non-linear structure, where it is employed iteratively. In Iteration 2, only four middle cables were used, since the outer four cables have not significant effect on adjustment for selected joints because their value of coefficient $\mathbf{Y}$ are very small, see Saeed [1].

Table 2: Displacement adjustment for Structure 2 without regard to the bar force.

\begin{tabular}{|c|c|c|c|c|c|c|c|c|c|}
\hline 1 & 2 & 3 & 4 & 5 & 6 & 7 & 8 & 9 & 10 \\
\hline \multirow[b]{2}{*}{ Joints } & \multirow[b]{2}{*}{$\begin{array}{l}\mathbf{d}_{\mathbf{p}} \\
(\mathrm{mm})\end{array}$} & \multirow[b]{2}{*}{$\begin{array}{l}\text { Req. d. } \\
(\mathrm{mm})\end{array}$} & \multicolumn{3}{|c|}{ Iteration 1} & \multicolumn{3}{|c|}{ Iteration 2} & \multirow[b]{2}{*}{ Cables } \\
\hline & & & $\begin{array}{l}\mathbf{e}_{\mathbf{o}} \mathbf{1} \\
(\mathrm{mm})\end{array}$ & $\begin{array}{l}\text { Theo. d. } \\
(\mathrm{mm})\end{array}$ & $\begin{array}{l}\text { Exp. d. } \\
(\mathrm{mm})\end{array}$ & $\begin{array}{l}\mathbf{e}_{\mathbf{o}} \mathbf{2} \\
(\mathrm{mm})\end{array}$ & $\begin{array}{l}\text { Theo. d. } \\
\text { (mm) }\end{array}$ & $\begin{array}{l}\text { Exp.d. } \\
(\mathrm{mm})\end{array}$ & \\
\hline $4 y$ & -7.5 & - & & -3.35 & -7.16 & & -5.53 & -7.12 & \\
\hline $7 y$ & -7.64 & - & & -3.44 & -6.36 & & -5.27 & -6.09 & \\
\hline $12 \mathrm{y}$ & -1.86 & - & -2.08 & -3.04 & -3.15 & 0 & 2.29 & 3.27 & 1 \\
\hline $13 \mathrm{y}$ & -3.23 & - & -0.06 & 0.85 & -2.11 & 0 & -0.16 & -1.56 & 2 \\
\hline $14 \mathrm{y}$ & -10.35 & - & -0.60 & -3.55 & -9.59 & -1.32 & -4.84 & -7.76 & 3 \\
\hline $15 \mathrm{y}$ & -14.03 & -10 & -2.40 & -5.8 & -13.12 & -4.95 & -6.72 & -9.84 & 4 \\
\hline $16 \mathrm{y}$ & -13.27 & -10 & -0.57 & -6.62 & -12.58 & -3.38 & -7.31 & -10.27 & 5 \\
\hline $17 \mathrm{y}$ & -8.55 & - & -0.14 & -4.35 & -7.08 & -0.82 & -5.18 & -6.15 & 6 \\
\hline $18 \mathrm{y}$ & -1.23 & - & 0.20 & 0.27 & 0.77 & 0 & -0.18 & -1.07 & 7 \\
\hline $19 \mathrm{y}$ & -1.86 & - & -2.88 & 2.81 & 3.83 & 0 & 2.18 & 3.96 & 8 \\
\hline \multicolumn{3}{|c|}{ Total actuation (mm) } & \multicolumn{3}{|l|}{8.93} & \multicolumn{3}{|l|}{10.47} & \\
\hline
\end{tabular}


4.2 Internal bar force control without regard to displacement

\subsubsection{Structure 1}

In this section, an experiment was carried out for adjusting internal bar force without regarding to joint displacement for Structure 1 for the loading case of $30.4 \mathrm{~N}$ downward on joints 10 to 17 on the deck beam as shown in Table 3. Columns 2 and 6 show the internal bar force before and after adjustment respectively, where only Cables 2 and 7 were chosen for control, since their internal force exceed a prescribed limit of $20 \mathrm{~N}$ for these two cables.

The results nicely show that the technique of linear adjustment works very well. There is a good correlation between theoretical and final experimental results and very close to the preferred tension bar force with the rms error only $0.44 \mathrm{~N}$. Cables 4 and 5 were not used in this experiment, since their value of coefficient $\mathbf{Z}$ are very small and have not noticeable effect on adjustment for selected cables Saeed [1].

\subsubsection{Structure 2}

In this Section Structure 2 was tested in order to adjust internal bar force of the two outer cables, while the structure was loaded with $15.3 \mathrm{~N}$ downward on joints 12 to 19 on the deck beam, and results are shown in Table 4. The two outer cables have the highest values of force, which are greater than the inner cables due to the geometry of the structure (force path). The load of Cables 1 and 8 were decided to be reduced from $38 \mathrm{~N}$ and $37 \mathrm{~N}$, respectively, as shown in Table 4 (Column 2), to 25 N. Columns 6 and 3 in Table 4 show that the experimental results after adjustment are almost the same as the target, with rms error of only $0.41 \mathrm{~N}$.

The theoretical and experimental internal forces in Cables 1 and 8 in Columns 5 and 6 respectively after adjustment have only a small discrepancy, even though the technique of adjustment is linear and structure model is geometrically nonlinear. So it can be concluded that the linear technique of the adjustment is almost applicable for adjusting internal bar force for those structures are geometrically nonlinear.

Table 3: Bar force adjustment for Structure 1 without regard to the displacement.

\begin{tabular}{llllll}
\hline 1 & 2 & 3 & 4 & 5 & 6 \\
\hline Cables & $\mathbf{t}_{\mathbf{p}} \cdot(\mathrm{N})$ & Req. t. $(\mathrm{N})$ & $\mathbf{e}_{\mathbf{o}}(\mathrm{mm})$ & Theo. t. $(\mathrm{N})$ & Exp. t. $(\mathrm{N})$ \\
\hline 1 & 23.1 & - & -1.47 & 35.2 & 36.9 \\
2 & 33.8 & 20 & 1.98 & 18.9 & 19.4 \\
3 & 27.9 & - & -1.29 & 41.1 & 42.3 \\
4 & 29.4 & - & 0 & 26.9 & 24.7 \\
5 & 29 & - & 0 & 27.3 & 27.5 \\
6 & 28.7 & - & -1.18 & 40.2 & 40.4 \\
7 & 32.8 & 20 & 1.81 & 20.0 & 19.8 \\
8 & 20.6 & - & -1.36 & 34.4 & 35.8 \\
Total actuation $(\mathrm{mm})$ & & 9.09 & & \\
\hline
\end{tabular}


Table 4: Bar force adjustment for Structure 2 without regard to the displacement.

\begin{tabular}{llllll}
\hline 1 & 2 & 3 & 4 & 5 & 6 \\
\hline Cables & $\mathbf{t}_{\mathbf{p}} \cdot(\mathrm{N})$ & Req. t. $(\mathrm{N})$ & $\mathbf{e}_{\mathbf{o}}(\mathrm{mm})$ & Theo. t. $(\mathrm{N})$ & Exp. t. $(\mathrm{N})$ \\
\hline 1 & 38.4 & 25 & 2.95 & 25.6 & 25.3 \\
2 & 15.8 & - & -1.93 & 23.3 & 26.9 \\
3 & 14.3 & - & 0.59 & 5.7 & 10.3 \\
4 & 15.4 & - & 0.02 & 16.3 & 17.0 \\
5 & 13.3 & - & 0.02 & 16.1 & 12.7 \\
6 & 11.2 & - & 0.52 & 6.6 & 5.5 \\
7 & 16.4 & - & -1.67 & 22.6 & 26.0 \\
8 & 37.1 & 25 & 2.60 & 25.2 & 25.5 \\
\multicolumn{7}{l}{ Total actuation $(\mathrm{mm})$} & & 10.30 & & \\
\hline
\end{tabular}

\section{CONCLUSION}

In this paper, two flexible geometrically linear and nonlinear structures (Structure 1) and (Structure 2) respectively were constructed. Both structures were tested theoretically and experimentally for the purpose of adjusting joint displacement and internal bar force via the linear techniques of adjustment, which were derived by Saeed and Kwan [11]. It was concluded that:

1. The shape of both Structure 1 and Structure 2 can be improved to some desired values, an adjustment, and some nodes can even be restored to the original positions.

2. The internal bar forces can be controlled to the desired amount of force limit to keep the members safe against compression and tension stress in struts and to avoid slack in cables.

3. Through the techniques of the internal bar force adjustment, the amount of force can be controlled down to zero, in case of replacing severely damage.

4. The applied techniques of linear adjustment are accurate for geometrically linear structures in controlling joint displacements and bar forces also for controlling internal bar forces for geometrically nonlinear structures. In contrast for controlling joint displacement of the nonlinear geometrical structures iterations are both necessary and sufficient for achieving the required displacement and force results.

\section{REFERENCES}

[1] Saeed, N.M., Prestress and Deformation Control in Flexible Structures. PhD Thesis, Cardiff University, 2014.

[2] Ziegler, F., Computational aspects of structural shape control. Computers \& Structures, 83(15), pp. 1191-1204, 2005.

http://dx.doi.org/10.1016/j.compstruc.2004.08.026 
[3] Shea, K., Fest, E. \& Smith, I.F.C., Developing intelligent tensegrity structures with stochastic search. Advanced Engineering Informatics, 16(1), pp. 21-40, 2002. http://dx.doi.org/10.1016/S1474-0346(02)00003-4

[4] Haftka, R.T. \& Adelman, H.M., An analytical investigation of shape control of large space structures by applied temperatures. AIAA Journal, 23(3), pp. 450-457, 1985. http://dx.doi.org/10.2514/3.8934

[5] Edberg, D.L., Control of flexible structures by applied thermal gradients. AIAA Journal, 25(6), pp. 877-883, 1987. http://dx.doi.org/10.2514/3.9715

[6] Burdisso, R.A. \& Haftka, R.T., Statistical analysis of static shape control in space structures. AIAA Journal, 28(8), pp. 1504-1508, 1990. http://dx.doi.org/10.2514/3.25245

[7] Kwan, A.S.K. \& Pellegrino, S., Prestressing a space structure. AIAA Journal, 31(10), pp. 1961-1963, 1993. http://dx.doi.org/10.2514/3.11876

[8] Du, J., Zong, Y., \& Bao, H., Shape adjustment of cable mesh antennas using sequential quadratic programming. Aerospace Science and Technology, 30(1), pp. 26-32, 2013. http://dx.doi.org/10.1016/j.ast.2013.06.002

[9] Weeks, C.J., Static shape determination and control of large space structures: I. The flexible beam. Journal of Dynamic Systems, Measurement, and Control, 106(4), pp. 261-266, 1984. http://dx.doi.org/10.1115/1.3140683

[10] Irschik, H., A review on static and dynamic shape control of structures by piezoelectric actuation. Engineering Structures, 24(1), pp. 5-11, 2002. http://dx.doi.org/10.1016/S0141-0296(01)00081-5

[11] Saeed, N.M. \& Kwan, A.S.K., Simultaneous displacement and internal force prescription in shape control of pin-jointed assemblies. AIAA Journal, 54(8), pp. 2499-2506, 2016. http://dx.doi.org/10.2514/1.J054811

[12] Saeed, N.M. \& Kwan, A.S.K., Concepts for morphing aerofoil sections using pantographic structures. Mobile and Rapidly Assembled Structures IV, 136, p. 279, 2014. http://dx.doi.org/10.2514/1.J054811

[13] You, Z., Displacement control of prestressed structures. Computer Methods in Applied Mechanics and Engineering, 144(1), pp. 51-59, 1997. http://dx.doi.org/10.1016/S0045-7825(96)01164-4 